\title{
An automated regional taste-testing system
}

\author{
PAUL HEBHARDT, RITU BAGLA, and RICHARD L. DOTY \\ University of Pennsylvania Medical Center, Philadelphia, Pennsylvania
}

\begin{abstract}
A fully programmable and portable automated regional taste-testing system is described. This system utilizes a glass stimulator held to the surface of the tongue by a mild vacuum. Temporally and spatially discrete trains of stimuli, delivered from a bank of glass reservoirs through microprocessorcontrolled Teflon solenoid valves and both glass and Tygon tubing, can be delivered to the lingual surface at millisecond durations. Rinses between stimuli are similarly programmed. The stimulus delivery is monitored at the surface of the tongue, using a capacitance sensor to alert the subject of stimulus delivery. An example of the application of this system is shown, in which we demonstrate that the detection threshold for $\mathrm{NaCl}$ is inversely related to stimulus duration by a power function.
\end{abstract}

The sense of taste plays a major role in determining the flavor of foods and serves to protect the organism from ingesting harmful substances. Taste aberrations-including debilitating and persistent sour and bitter taste phantoms that compromise food intake, nutrition, and the quality of life-are common in the elderly population (Mott \& Leopold, 1991). Accurate clinical assessment of taste function is essential in order to localize the source of dysfunction and to apply appropriate remedial measures.

Although whole-mouth taste testing is widely used in clinical situations, such testing is insensitive to most regional deficits in the oral cavity (Bartoshuk, 1989). For example, numerous medical conditions selectively influence a given taste-related nerve (e.g., most cases of Bell's palsy affect only the facial nerve [CN VII] unilaterally [Taverner, 1955]), requiring refined assessment of gustatory function. Furthermore, whole-mouth testing seems to be less sensitive than regional testing to the influences of aging (Matsuda \& Doty, 1995). This is presumably due, in part, to the fact that whole-mouth testing recruits taste fibers from several cranial nerves (e.g., the facial [CN VII], the glossopharyngeal [CN IX], and the vagus $[\mathrm{CN} \mathrm{X}]$ ), whereas regional testing typically does not.

In the clinic, regional testing of the tongue has traditionally been performed with electrogustometry (Krarup, 1958), small pieces of filter paper (Tomita, Ikeda, \& Okuda, 1986), cotton swabs (Bartoshuk, Desnoyers, O'Brien, Gent, \& Catalanotto, 1985), or pipettes (Deems et al., 1991). Unfortunately, electrogustometry is limited in that it does not elicit the entire range of taste sensations (e.g., sweet, salty, etc.), presumably influencing only those receptor mechanisms responsive to ionic (e.g., $\mathrm{NaCl}$, cit-

This research was supported by Grant NIDCD PO1 000161 from the National Institutes of Health. We thank C. Nelson Dorny, James Graham, William Irby, Toshi Matsuda, and Steven Wyzykiewicz for their technical assistance. Correspondence concerning this article should be addressed to R. L. Doty, Smell and Taste Center, University of Pennsylvania Medical Center, 5 Ravdin Bldg., 3400 Spruce Street, Philadelphia, PA 19104 (e-mail: doty@mail.med.upenn.edu). ric acid) stimuli (Frank \& Smith, 1991; Salada, Raj, \& Doty, 1991). With the possible exception of procedures in which tastants are thickened with cellulose (see, e.g., Kroger, Doty, \& Hoffman, 1997), procedures that present drops of solution to the tongue (see, e.g., Henkin \& Christiansen, 1966) do not allow for precise control of the spatial extent of the stimulus on the tongue's surface, and those that directly apply tastants via cotton swabs or by other mechanical means have the potential for confounding gustatory and somatosensory stimulations. Presentation of stimuli with small pieces of filter paper are limited by poor diffusion of the stimulus from the filter paper and by variation in mucus thickness on the tongue's surface.

Several studies suggest that well-defined temporal and spatial regional stimulation of the tongue can be established in the laboratory setting, although most such studies have evaluated only suprathreshold responses. For example, Kelling and Halpern (1983) regionally stimulated the tongue, using a closed-flow system in which liquid flowed through a $39.3-\mathrm{mm}^{2}$ elliptical opening in the bottom wall of a polypropylene tube. These investigators found that intensity magnitude estimates increase as stimulus duration increases from 0.1 to $1.0 \mathrm{sec}$. Their device, which was used in a number of subsequent studies that expanded these durations (Kelling \& Halpern, 1986, 1987, 1988; Lester \& Halpern, 1979), employed elements of earlier similar devices (i.e., Meiselman, Bose, \& Nykvist, 1972; Meiselman \& Halpern, 1973). More recently, Zuniga et al. (1993) attached a polyethylene chamber with a $43-\mathrm{mm}^{2}$ orifice to the anterior tongue, using Krazy Glue, and established detection thresholds to citric acid in 84 people, using a forced-choice paradigm. Stimuli $10 \mathrm{sec}$ in duration were employed. An inverse relationship was found between threshold values and the number of fungiform papillae.

\section{DESCRIPTION OF A NEW REGIONAL TASTE-TESTING SYSTEM}

In this paper, we describe a new automated regional taste-testing system (termed the University of Pennsylva- 
nia Regional Automated Taste Testing System, or RATTS; see Figure 1) that accommodates several sizes of glass tongue stimulators and easily provides different concentrations of tastants for the measurement of gustatory detection thresholds. The RATTS is a further development of a microprocessor-controlled gustometer described by Matsuda and Doty (1995) and was designed to allow precise presentation of a wide range of taste stimuli to discrete tongue regions. This system differs from most previous systems in (1) providing computer control over the stimulus and rinse durations, (2) employing interchangeable glass stimulating devices, held to the tongue by vacuum, (3) supplying multiple tastant channels amenable to threshold stimulus presentation, and (4) being relatively portable, since it is mounted on a mobile Topcon AIT-10B Electric Cart (Topcon Corp., Tokyo). This device automatically delivers timed trains of stimulus pulses (boluses) and water rinses from 13 gravity-fed solution reservoirs to a given glass stimulation device attached to the tongue. After flowing over the tongue surface, the solutions are evacuated into a disposable plastic cup (Figure 1). Three stimulator sizes are presently available: $12.5,25.0$, and $50.0 \mathrm{~mm}^{2}$ (Figure 2). The $250-\mathrm{ml}$ reservoirs are made of Pyrex glass. The solution from each reservoir flows through a 24-VDC three-way Teflon solenoid valve (General Valve Corp., Fairfield, NJ) into a common, 5.6-cm-long Pyrex glass collecting tube (Figure 3 ). The solenoid valves are vented individually, to eliminate the vacuum that forms as a result of the opening and closing of the valves and, hence, to avoid formation of small bubbles in the solution streams. Because of its low porosity and hydraulic resistance, glass is used throughout the system, wherever possible, facilitating laminar solution flow in the delivery of stimuli and minimizing stimulus contamination of the system. Once in the collecting tube, a stimulus pulse, or bolus, is moved through the tube to the tongue by an air pump. The current into the air pump is controlled by a variable resistor so that the air flow rate can be varied, allowing for simple temporal control of stimulus duration at the tongue's surface. The stimulus solution passes through a capacitance sensor located at the edge of the glass applicator. This sen-

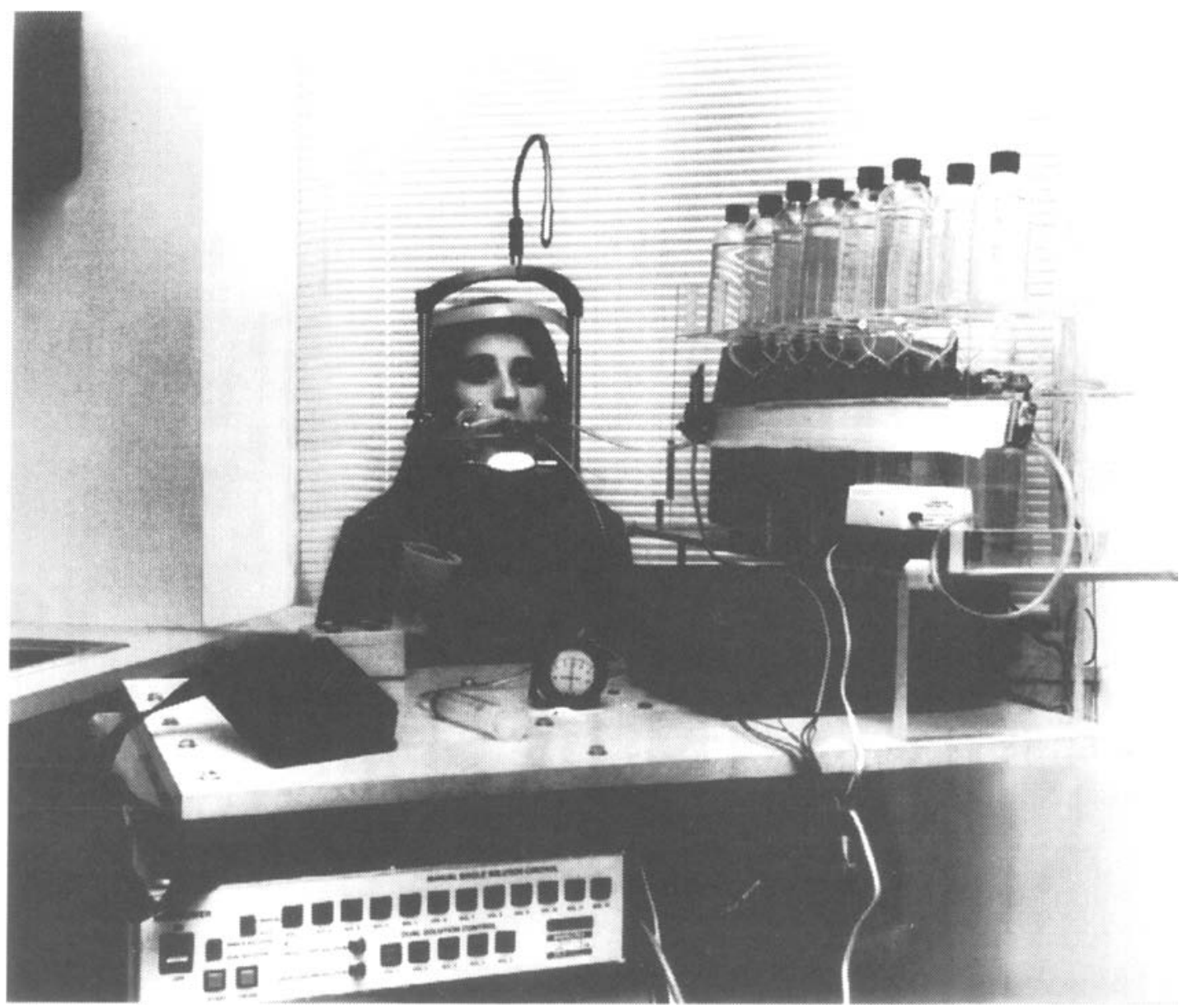

Figure 1. The University of Pennsylvania Regional Automated Taste Testing System (RATTS), with the subject seated comfortably and the glass stimulation device, a suction gauge, and the microprocessor in place. The table can be moved up or down electrically to accommodate the subject's height. The flexible extension from the top of the headrest contains a light that cues stimulus delivery. 


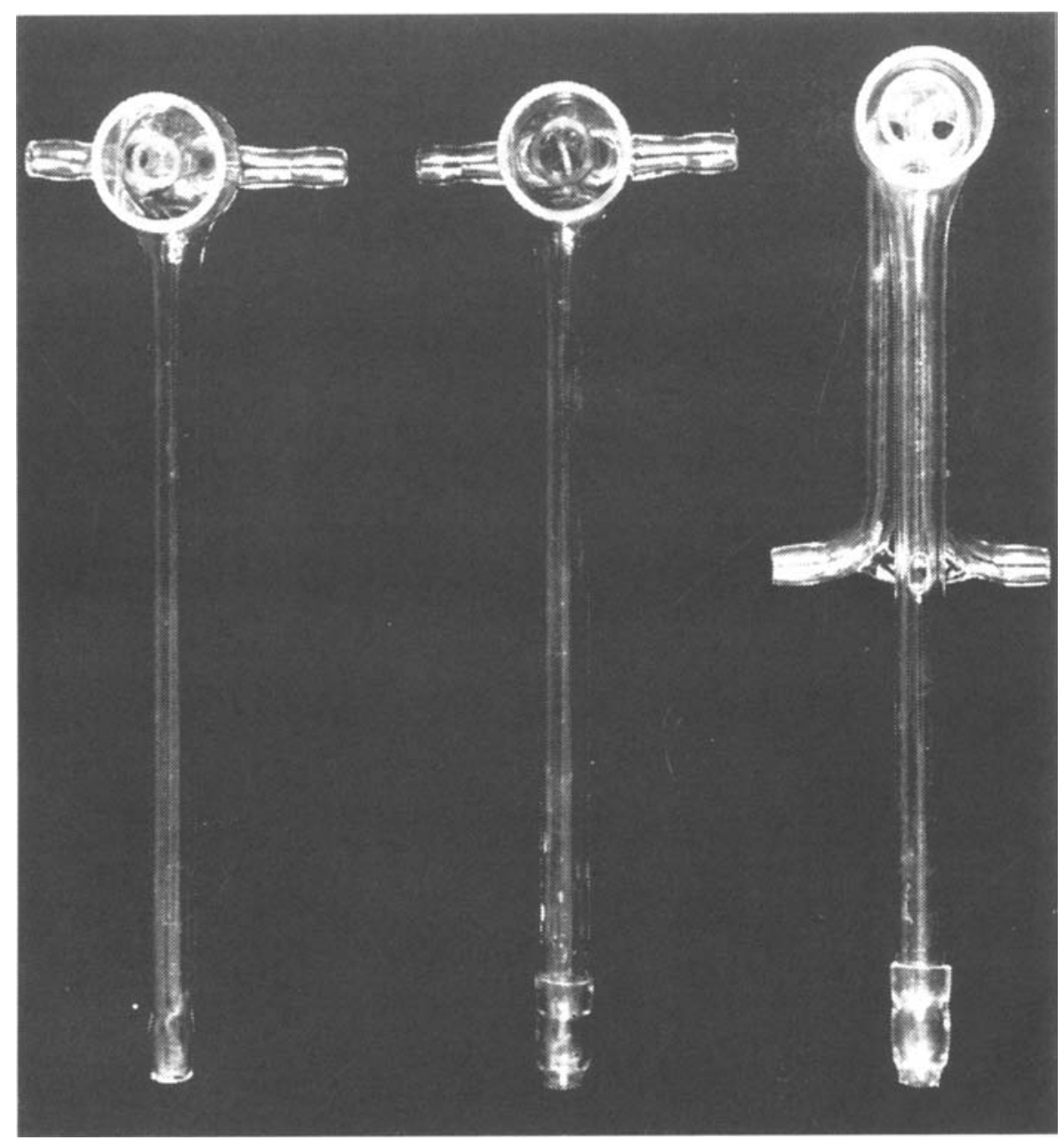

Figure 2. Glass stimulation devices viewed from the bottom. The stimuli flow through the inner chambers, which, from left to right, provide three different areas of stimulation: $12.5,25$, and $50 \mathrm{~mm}^{2}$. A vacuum surround, calibrated with a DWYER Minihelic-2 differential pressure gauge, holds the device on the subject's tongue. From "Regional Taste Sensitivity to NaCl: Relationship to Subject Age, Tongue Locus, and Area of Stimulation," by T. Matsuda and R. $L$. Doty, 1995, Chemical Senses, 20, p. 286. Copyright 1995 by Oxford University Press. Reprinted with permission.

sor activates a relay circuit and light, which cues the subject as to stimulus delivery. The subject signals whether a stimulus is detected by pressing a response button.

The control of stimulus delivery parameters and the recording of subject responses is performed by a programmable logic controller (PLC; ATCOM Interactive Controller 64, Automatic Timing and Controls Company, Inc., King of Prussia, PA). This device is a solid state industrial control system of remarkable durability that incorporates microprocessor technology to control a series of relay circuits (see Figure 4). Sixty-four input/ output connections are provided that can be individually designated as either $120 \mathrm{~V} \mathrm{AC}$ or $24 \mathrm{~V} \mathrm{DC}$. This accommodates the system's requirement for both types of power (see below) and allows the system to be operated without a computer, aiding in its portability. A design feature of the ATCOM 64 is its use of its own language (SNAP) to control inputs and outputs. This language is much more flexible than the ladder logic of many other PLCs (e.g., it allows for IF THEN logic, as well as for the ability to replay a random number sequence). The ATCOM 64 is powered by $120 \mathrm{~V} \mathrm{AC}$. Configuring the ATCOM for each type of output (i.e., for the solenoid valves, the air pump, and the capacitance sensor; see Figure 4) simply requires installing a 120 -VAC or 24 -VDC module into the controller and supplying that module with an appropriate power source.

The fully programmable capability of the RATTS, unlike the situation with most other devices described in the literature, allows for rapid and straightforward manipulation of stimulus parameters useful for assessing taste function, including stimulus duration, flow rate, in- 


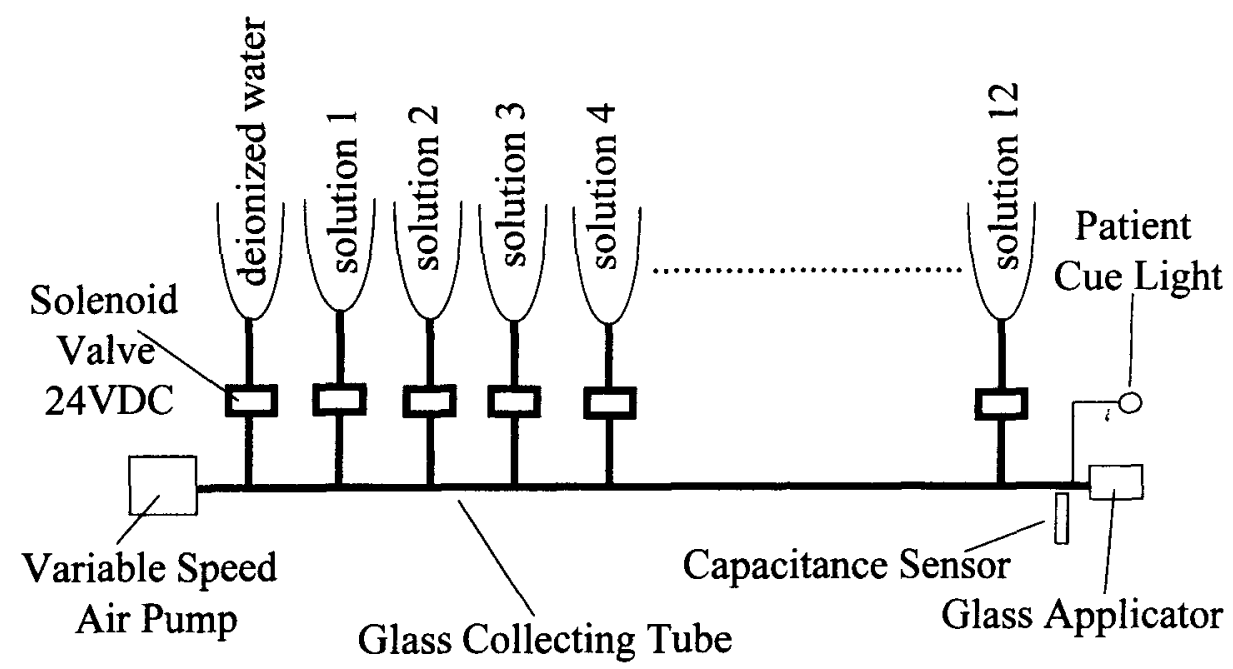

Figure 3. Diagram of the basic configuration of the Regional Automated Taste Testing System. See the text for details.

terstimulus interval, stimulus concentration step size, and rinse times. In its current configuration, the system is programmed so that only the tastant and the blank comparison stimuli activate the capacitance sensor, thereby accurately signaling their time of delivery. The programmable feature also allows for the provision of a consistent constant time interval between the blank and the target stimuli across trials, regardless of the different distances of the solution reservoirs from the tongue within the delivery system. Without such a provision, confounding temporal cues that would signal the stimuli involved might be discerned by the subject.

To assess the flow of stimulus pulses, or boluses, through the system, as well as to determine the stimulus durations, we performed the following two pilot studies.
First, we added blue food dye (McCormick \& Co., Hunt Valley, MD) to the stimuli and found that no discernible residual solution remained in the system or the applicator. Second, we employed conductivity cells, analogous to those described by Halpern (1985) and Kelling and Halpern (1986) for their closed flow delivery system, to measure the programmed stimulus durations. The electrodes were two $0.3-\mathrm{mm}$-diameter platinum wires, set opposite one another 1-2 mm apart. They were inserted through the $3.175-\mathrm{mm}$ (ID), 6.35-mm (OD) Tygon tube connecting the apparatus to the tongue application at a distance $2 \mathrm{~cm}$ proximal to the applicator.

As in the study by Kelling and Halpern (1986), a 1-V, $1-\mathrm{kHz}$ sine wave was sent to the conductivity cell via unshielded leads, using a balanced constant current circuit.

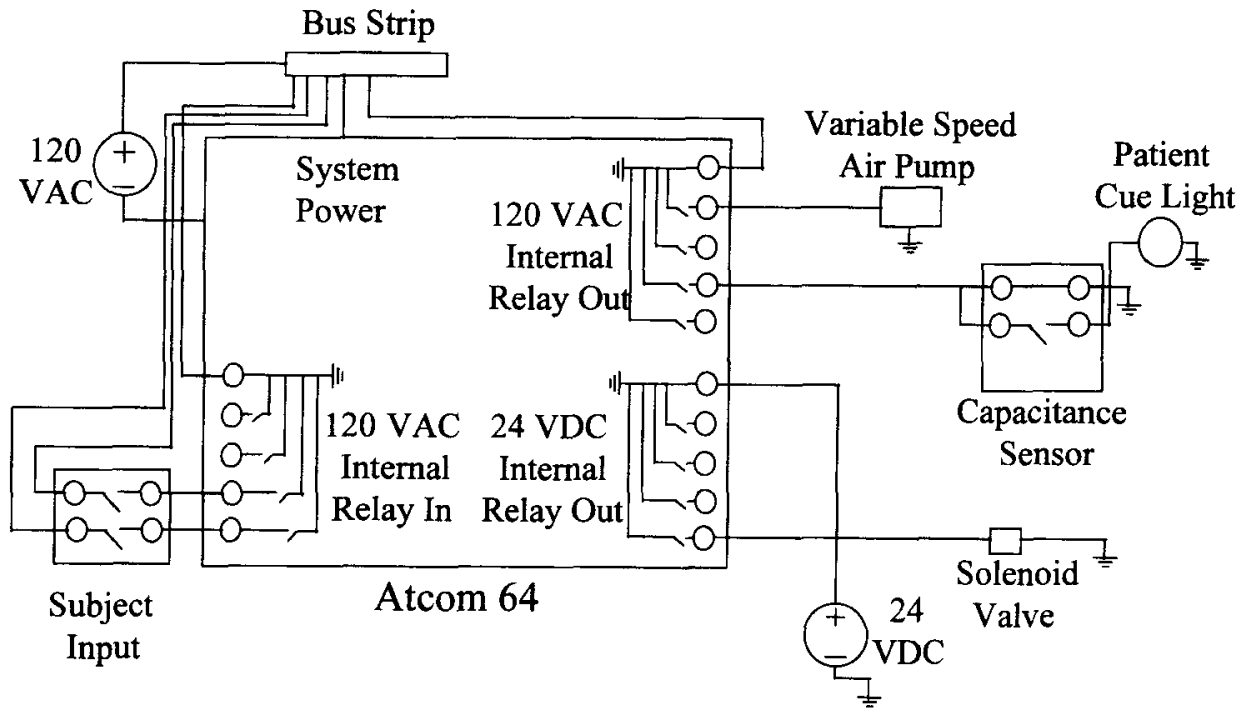

Figure 4. Wiring diagram of the Regional Automated Taste Testing System. See the text for details. 
The potential difference between the two electrodes was measured with a 1-M $\Omega$ input impedance differential preamplifier (Tektronix ADA400A) in parallel with the conductivity cell. The output of the amplifier was displayed on an oscilloscope. Solution presentation was always preceded by a $10-\mathrm{sec}$ deionized water rinse.

Measurements were made to evaluate the nature of the stimulus rise and fall times for the stimulus durations of $0.75,1.00$, and $1.50 \mathrm{sec}$ programmed into the ATCOM. The conductivities were measured for a $3.16-\mathrm{mM}$ concentration of $\mathrm{NaCl}$. Asycan be seen in Figure 5, the stimulus functions reflected a sharp rise time $(<10 \mathrm{msec})$ and a more tapered decay time across the three stimulus durations. As in the study by Kelling and Halpern (1986), the stimulus durations estimated from the oscilloscope tracings were considerably longer ( $20 \%$ to $40 \%$ ) than the

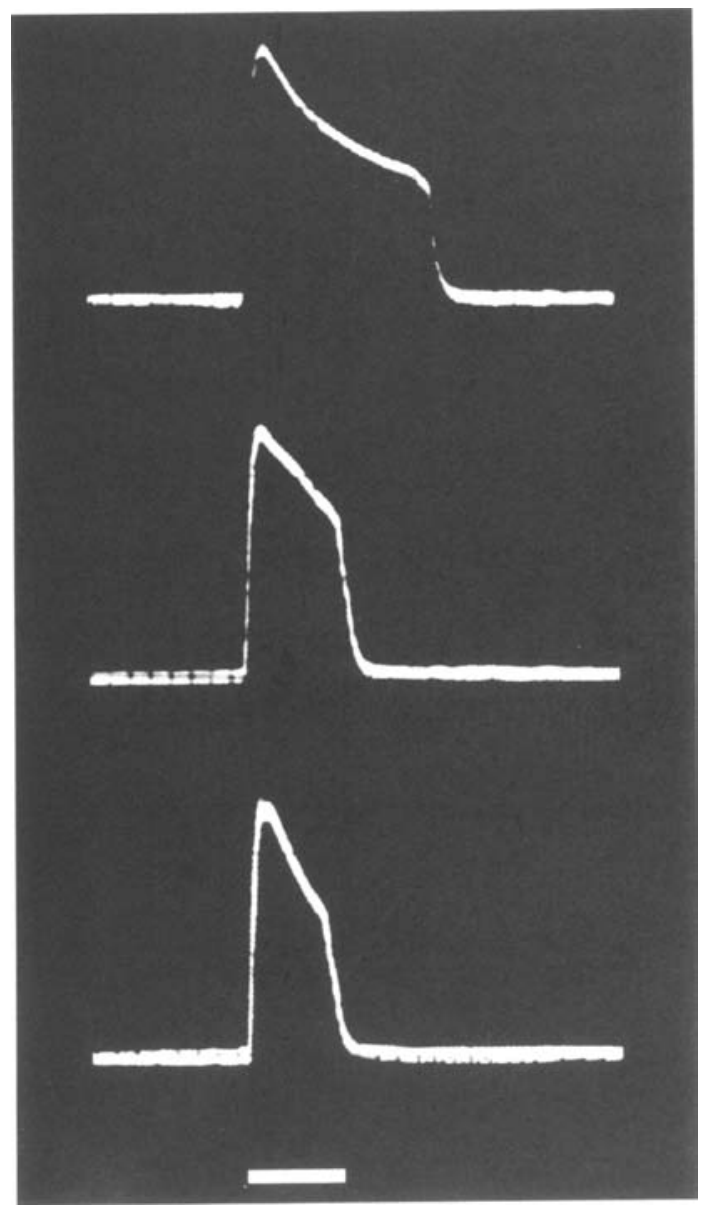

Figure 5. Photographs of oscilloscope tracings showing conductivity voltages of $3.16-\mathrm{mM} \mathrm{NaCl}$ solution flowing through a conductivity cell at intended pulse durations, from bottom to top, of $0.75,1.00$, and 1.50 sec. The bar represents $1.0 \mathrm{sec}$. The conductivity cell estimate for the 0.75 -sec-duration stimulus was $\sim 1.00 \mathrm{sec}$, for the 1.00-sec-duration stimulus $\sim 1.20 \mathrm{sec}$, and for the 1.5-sec-duration stimulus $\sim 2.10 \mathrm{sec}$. Stimulus presentations were preceded by a 10-sec deionized water rinse.

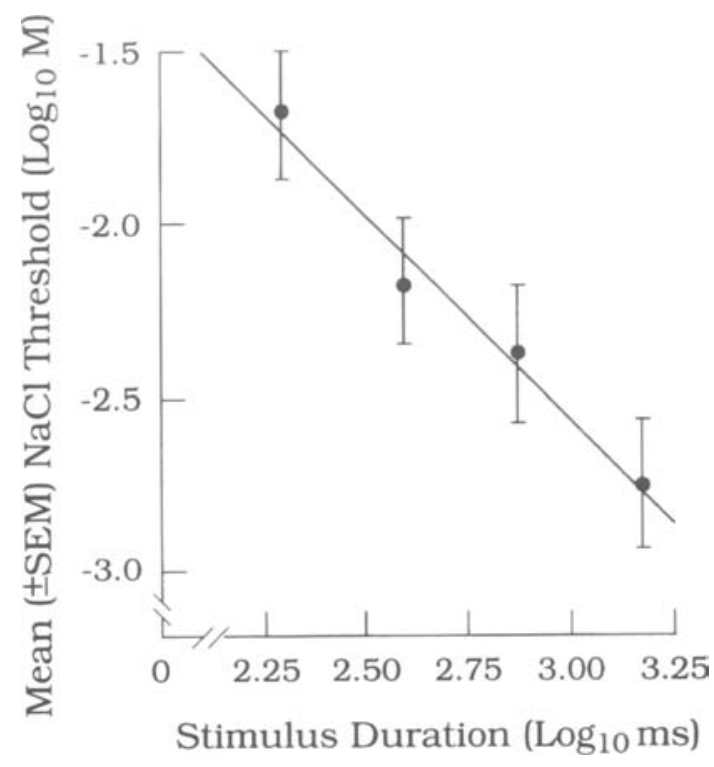

Figure 6. Mean $( \pm S E M) \mathrm{NaCl}$ detection threshold values as a function of stimulus duration plotted on $\log -\log$ axes. The four data points, from left to right, correspond to 0.2-, 0.4-, 0.75-, and 1.5-sec programmed durations. See the text for details. From "Influence of Stimulus Duration on a Regional Measure of $\mathrm{NaCl}$ Taste Sensitivity," by R. Bagla, B. Klasky, and R. L. Doty, 1997, Chemical Senses, 22, p. 173. Copyright 1997 by Oxford University Press. Reprinted with permission.

programmed durations, presumably reflecting a delay in stimulus removal from the Tygon tubing (Figure 5). However, the relative stimulus durations were very accurate. For example, the percentage of error between the empirically derived 0.75 - and 1.0 -sec-duration stimuli was only $4 \%$, and that between the 0.75 - and 1.5 -sec-duration stimuli was $5 \%$.

\section{AN EXAMPLE STUDY USING THE RATTS}

The utility of the RATTS is clearly demonstrated in a recent study of 12 college students (mean age $=21.83$ years, $S D=2.69$ ), in which $\mathrm{NaCl}$ thresholds were determined on a $25-\mathrm{mm}^{2}$ tongue region at programmed stimulus durations ranging from 0.2 to $1.5 \mathrm{sec}$ (Bagla, Klasky, \& Doty, 1997). A forced-choice two-alternative single staircase detection threshold paradigm was employed. The stimuli were presented using a two-down, one-up rule (Levitt, 1970), with the exception that five consecutive correct responses were required for the first reversal. The first stimulus was presented at the $0.36-\mathrm{mM}$ concentration of $\mathrm{NaCl}$. Subsequent stimuli were presented at half-log steps ranging from $3.16 \times 10^{-5} \mathrm{M}$ to $3.16 \mathrm{M}$. Flow rates of $1.6 \mathrm{ml} / \mathrm{sec}$ were employed. The participants were asked to decide which of two trials (deionized water or a concentration of sodium chloride $[\mathrm{NaCl}]$ dissolved in deionized water $\left[\mathrm{H}_{2} \mathrm{O}\right]$ ) elicited the stronger sensation. For each test trial, the blank and $\mathrm{NaCl}$ solutions were presented in random order, with a rinse 
of deionized water preceding each test solution. No feedback as to the correctness of the responses was provided. The intertrial interval was $20 \mathrm{sec}$. The mean of the last four of seven reversals served as the threshold estimate.

As is shown in Figure 6, the $\mathrm{NaCl}$ thresholds were inversely related to stimulus duration. This relationship was well described by the power function, $c=9.638 d^{-1.18}$, where $c$ is the molar concentration at threshold and $d$ is the programmed stimulus duration in milliseconds $\left(r^{2}=\right.$ $.979, p=.011)$.

\section{SUMMARY}

The present paper describes a device that allows for precise, temporally discrete automatic presentation of taste stimuli of varying concentrations and quality to small, well-defined regions of the tongue. This system, which overcomes a number of problems of earlier regional taste-testing techniques, can be used for a variety of applications in which accurate stimulus control is desired. Applications of this system include not only basic studies of the spatial and temporal properties of gustatory functions of various tongue regions, but also clinical studies examining subtle taste deficits that otherwise might go undetected.

\section{REFERENCES}

BaGla, R., Klasky, B., \& Doty, R. L. (1997). Influence of stimulus duration on a regional measure of $\mathrm{NaCl}$ taste sensitivity. Chemical Senses, 22, 171-175.

Bartoshuk, L. M. (1989). Taste: Robust across the age span? Annals of the New York Academy of Sciences, 561, 65-75.

Bartoshuk, L. M., Desnoyers, S., O'Brien, M., Gent, J. F., \& CataLANOTTO, F. C. (1985). Taste stimulation of localized tongue areas: The Q-tip test. Chemical Senses, 10, 453.

Deems, D. A., Doty, R. L., Settle, R. G., Moore-Gillon, V., Shaman, P., Mester, A. F., Kimmelman, C. P., Brightman, V. J., \& SNOw, J. B. (1991). Smell and taste disorders, a study of 750 patients from the University of Pennsylvania Smell and Taste Center. Archives of Otolaryngology: Head \& Neck Surgery, 117, 508-528.

Frank, M. D., \& SMITH, D. V. (1991). Electrogustometry: A simple way to test taste. In T. V. Getchell, R. L. Doty, L. M. Bartoshuk, \& J. B. Snow, Jr. (Eds.), Smell and taste in health and disease (pp. 503-514). New York: Raven.

HALPERN, B. R. P. (1985). What to control in studies of taste. In H. Meis- elman \& R. Rivlin (Eds.), Clinical measurement of taste and smell (pp. 201-262). New York: Macmillan.

Henkin, R. I., \& Christiansen, R. L. (1966). Taste localization on the tongue, palate and pharynx of normal man. Journal of Applied Physiology, 22, 316-320.

Kelling, S. T., \& Halpern, B. P. ( 1983). Taste flashes: Reaction times, intensity, and quality. Science, 219, 412-414.

Kelling, S. T., \& HalPern, B. P. (1986). The physical characteristics of open flow and closed flow taste delivery apparatus. Chemical Senses, 11, 89-103.

Kelling, S. T., \& HalPERN, B. P. (1987). Taste judgements and gustatory stimulus duration: Simple taste reaction times. Chemical Senses, 12, 543-562.

Kelling, S. T., \& HaLPERN, B. P. (1988). Taste judgements and gustatory stimulus duration: Taste quality, taste intensity, and reaction time. Chemical Senses, 13, 559-586.

KRARUP, B. (1958). Electro-gustometry: A method for clinical taste examinations. Acta Otolaryngologica, 49, 294-305.

Kroger, H., Doty, R, L., \& Hoffman, K. (1997). Development of a regional taste sensitivity test using isointense and isoviscid stimuli. Chemical Senses, 22, 725-726.

LESTER, B., \& HALPERN, B. P. (1979). Effect of stimulus presentation duration on gustatory reaction time. Physiology \& Behavior, 22, 319324.

LEVITT, H. (1970). Transformed up-down methods in psychophysics. Journal of the Acoustical Society of America, 49, 467-477.

MatsudA, T., \& Doty, R. L. (1995). Regional taste sensitivity to $\mathrm{NaCl}$ : Relationship to subject age, tongue locus, and area of stimulation. Chemical Senses, 20, 283-290.

Meiselman, H. L., Bose, H., \& Nykvist, W. (1972). Effect of flow rate on taste intensity responses in humans. Physiology \& Behavior, 9 , 35-38.

Meiselman, H. L., \& Halpern, B. P. (1973). Enhancement of taste intensity through pulsatile stimulation. Physiology \& Behavior, 11, 713-716.

MotT, A. E., \& Leopold, D. A. (1991). Disorders in taste and smell. Medical Clinics of North America, 75, 1321-1353.

SAlAdA, J. A., RAJ, J. M., \& Doty, R. L. (1991). Differential sensitivity of tongue areas and palate to electrical stimulation: A suprathreshold cross-modal matching study. Chemical Senses, 16, 483-489.

TAVERNER, D. (1955). Bell's palsy: A clinical and electromyographic study. Brain, 78, 209-228.

TOMITA, H., IKEDA, M., \& OKUDA, Y. (1986). Basis and practice of clinical taste examinations. Auris, Nasus, Larynx, 13(Suppl. I), S1-S15.

Zuniga, J. R., Davis, S. H., Englehardt, R. A., Miller, I. J., JR., SChiffMan, S. S., \& PHILlips, C. (1993). Taste performance on the anterior human tongue varies with fungiform taste bud density. Chemical Senses, 18, 449-460.

(Manuscript received February 28, 1998; revision accepted for publication September 22, 1998.) 